18

\title{
Синхротронные, рентгеновские и электронно-микроскопические исследования каталитических систем на основе многостенных углеродных нанотрубок, модифицированных наночастицами меди
}

\author{
(C) В.Н. Сивков ${ }^{1}$, А.М. Объедков ${ }^{2}$, О.В. Петрова ${ }^{1,3}$, С.В. Некипелов ${ }^{1,3}$, А.Е. Мингалева ${ }^{1,4}$, К.В. Кремлев ${ }^{2}$, \\ Б.С. Каверин ${ }^{2}$, Н.М. Семенов ${ }^{2}$, А.В. Кадомцева ${ }^{5}$, С.А. Гусев ${ }^{6}$, П.А. Юнин ${ }^{6}$, Д.А. Татарский
}

${ }^{1}$ Федеральный исследовательский центр Коми научный центр УрО РАН, Сыктывкар, Россия

${ }^{2}$ Институт металлоорганической химии им. Г.А. Разуваева РАН,

Нижний Новгород, Россия

${ }^{3}$ Сыктывкарский государственный университет им. Питирима Сорокина,

Сыктывкар, Россия

${ }^{4}$ Институт фризики им. В.А. Фока Санкт-Петербургского государственного университета, Санкт-Петербург, Россия

${ }^{5}$ Приволжский исследовательский медицинский университет Министерства здравоохранения Российской Федерации, Нижний Новгород, Россия

${ }^{6}$ Институт фозики микроструктур РАН, Нижегородская область, Россия

E-mail: svn@dm.komisc.ru

Поступила в Редакцию 14 ноября 2018 г.

В окончательной редакции 14 августа 2019 г.

Принята к публикации 14 августа 2019 г.

Обсуждаются результаты исследований методами электронной микроскопии, рентгеновской дифрактометрии и ультрамягкой рентгеновской спектроскопии композита на основе многостенных углеродных нанотрубок, на внешнюю поверхность которых путем пиролиза формиата меди осаждались наноразмерные частицы меди. Установлено, что в инертной атмосфере аргона наночастицы меди осаждаются на поверхности МУНТ в виде наночастиц разного размера, состоящих из ядра металлической меди и оболочки из закиси меди $\mathrm{Cu}_{2} \mathrm{O}$. Однако после выноса на атмосферу, на поверхности наночастиц меди формируется слой оксида меди $\mathrm{CuO}$. Показано, что хорошая адгезия наночастиц меди на поверхности МУНТ обеспечивается образованием химической связи между атомами углерода внешнего графенового слоя нанотрубки и атомами кислорода закиси меди $\mathrm{Cu}_{2} \mathrm{O}$, изначально покрывающей металлическое ядро наночастиц.

Ключевые слова: углеродные нанотрубки, MOCVD, наноразмерные частицы меди, NEXAFS.

DOI: 10.21883/FTT.2020.01.48756.315

\section{1. Введение}

Гибридные материалы на основе многостенных углеродных нанотрубок (МУНТ), поверхность которых декорирована различными металлосодержащими наночастицами, представляют собой новый класс функциональных наноматериалов. Роль МУНТ заключается в их способности стабилизировать высокодиспергированные наночастицы металлов, карбидов металлов или оксидов металлов, что в конечном итоге приводит к более высоким удельным площадям поверхности осаждаемых наночастиц. Декорирование поверхности МУНТ наноразмерными металлосодержащими частицами и покрытиями позволяет существенно изменять их физико-химические свойства [1]. Гибридные материалы на основе МУНТ, поверхность которых декорирована металлосодержащими наночастицами (металлами, окислами металлов или карбидами металлов), имеют большую перспективу применения в качестве нанодисперсных наполнителей металлических, керамических или полимерных материа- лов, а также в фотокатализе, гетерогенном катализе, газовых сенсорах и в электрохимических конденсатоpax [2]. В частности, значительный интерес вызывает использование гибридного материала на основе МУНТ, поверхность которых декорирована наночастицами меди (нанокомпозит $\mathrm{Cu} / \mathrm{MУHT),} \mathrm{в} \mathrm{качестве} \mathrm{катализатора}$ восстановления тетрахлорида германия водородом [3]. Авторами было показано, что применение такого катализатора позволило снизить температуру проведения процесса с $1073 \mathrm{~K}$ до $723 \mathrm{~K}$ и увеличить степень конверсии тетрахлорида германия до $98 \%$.

Важным преимуществом гибридных материалов является большое разнообразие используемых маршрутов синтеза. В настоящее время основными методами синтеза гибридных материалов являются электрохимическое восстановление солей металлов с применением зольгель процесса, химическое осаждение из паровой фазы металлоорганических соединений (MOCVD-метод) и физическое осаждение (электроннолучевое напыление, термическое напыление и др.). Среди этих методов 
особое место занимает MOCVD-метод, в котором металлосодержащие наночастицы осаждаются на поверхность МУНТ при пиролизе паров металлоорганического соединения (МОС) в результате химических реакций на поверхности МУНТ. Преимущества этого метода перед другими заключаются в том, что существует большой выбор летучих МОС, метод работает при относительно невысоких температурах (573-873 K), летучие продукты реакции выводятся из зоны осаждения твердой фазы покрытия, достигается высокая скорость осаждения и регулирования состава покрытия. Этот метод был использован нами ранее для формирования металлосодержащих наноструктурированных покрытий на поверхности МУНТ, как в виде сплошного слоя наноразмерной толщины, например, пиролитического железа (Fе/МУНТ) [4,5], хрома (Cr/МУНТ) [6], карбида титана (ТіС/МУНТ) [7], так и в виде металлосодержащих наночастиц, например, рения (Re/MУHT) [8], алюминия (Al/MУНТ) [9] и биметаллических ренийвольфрамовых нанодендритов (Re-W/MУHT) [10]. Таким образом, используемый нами ранее метод MOCVD оказался весьма удачным для получения нанокомпозитов на основе МУНТ, поверхность которых декорирована различными металлосодержащими покрытиями или наночастицами. Однако в работе [3] мы отошли от привычного использования металлоорганических соединений для целей получения гибридных наноматериалов. Для синтеза нанокомпозита $\mathrm{Cu} / \mathrm{MУНT} \mathrm{в} \mathrm{качестве} \mathrm{прекур-}$ сора мы использовали неорганическое соединение формиат меди (соль меди и муравьиной кислоты). Методика синтеза гибридного наноматериала значительно отличается от ранее используемой нами технологии MOCVD. Нанокомпозит Cu/MУНT был получен пиролизом формиата меди, предварительно нанесенного на поверхность МУНТ из водного раствора. Пиролиз проводили в токе аргона. В работе [3] были проведены экспериментальные исследования влияния каталитической системы на основе нанокомпозита $\mathrm{Cu} / \mathrm{MУHT}$ на кинетику каталитического восстановления тетрахлорида германия водородом. В промышленности широко используется „хлоридный“ метод получения высокочистого германия [11]. Однако проблемой этой технологии является низкий выход германия (не выше 70\%), что делает „хлоридную технологию“ достаточно трудоемкой и затратной. Наши исследования показали, что введение в зону реакции катализатора на основе нанокомпозита $\mathrm{Cu} / \mathrm{MУНТ} \mathrm{позволяет} \mathrm{снизить} \mathrm{температуру} \mathrm{проведения}$ реакции и достичь конверсии по тетрахлориду германия на уровне 98\%. Это существенный результат для практического применения „хлоридной технологии“ получения высокочистого монокристаллического германия [12].

В настоящей работе приводятся результаты исследований образцов нанокомпозита $\mathrm{Cu} / \mathrm{MУНТ} \mathrm{методами}$ сканирующей электронной микроскопии (СЭМ), просвечивающей электронной микроскопии высокого разрешения (ПЭМВР), рентгенофазового анализа (РФА) и ультрамягкой рентгеновской (УМР) спектроскопии с применением синхротронного излучения (СИ). При этом особое внимание акцентировалось на изучении ближней тонкой структуры рентгеновских спектров поглощения (near edge x-ray absorption fine structure, NEXAFS) в области $\mathrm{C} 1 s$ - и $\mathrm{Cu} 2 p$-порогов ионизации, так как NEXAFS-спектроскопия позволяет характеризовать состояние внешней поверхности МУНТ, интерфейс МУНТ - металл и поверхность металлосодержащей наночастицы без разрушения и модификации [5,13]. Наряду с этим NEXAFS-исследования позволяют определить эффективную площадь покрытия металлосодержащими наночастицами, их химический состав, состояние поверхности МУНТ и исследовать взаимодействие поверхности МУНТ с металлосодержащей наночастицей [4-6].

\section{2. Методы исследования}

Синтез МУНТ осуществлялся методом MOCVD с использованием в качестве прекурсоров ферроцена и толуола в печи трубчатого типа. Аппаратура и условия синтеза МУНТ подробно описаны ранее $[5,14]$. В качестве прекурсора синтеза наночастиц меди использовали формиат меди. Для нанесения формиата меди на поверхность МУНТ навеску формиата меди в количестве $150 \mathrm{mg}$ помещали в стеклянный стакан и растворяли при комнатной температуре в $100 \mathrm{ml}$ дистиллированной воды с добавлением $30 \mathrm{mg}$ порошка МУНТ, который обрабатывали в ультразвуковой ванне в течениие $3 \mathrm{~h}$ и затем высушивали при температуре $368 \mathrm{~K}$ до выпадения сухого порошкообразного осадка. Синтез гибридного материала проводили в реакторе из пирексового стекла в виде ампулы с боковым отводом при температуре $473 \mathrm{~K}$ в токе аргона высокой чистоты. Осаждение наночастиц меди на поверхность МУНТ при пиролизе формиата меди с образованием нанокомпозита $\mathrm{Cu} / \mathrm{MУHT} \mathrm{проходило} \mathrm{по} \mathrm{схеме}$

$$
(\mathrm{H}-\mathrm{COO})_{2} \mathrm{Cu} \rightarrow \mathrm{Cu}+2 \mathrm{CO}_{2}+\mathrm{H}_{2} .
$$

Нанокомпозит $\mathrm{Cu} / \mathrm{MУНТ} \mathrm{после} \mathrm{извлечения} \mathrm{из} \mathrm{реакто-}$ ра не требовал дальнейшей обработки в растворителях и был готов к дальнейшему применению. Хранение нанокомпозита проводили в объеме, заполненном аргоном высокой степени чистоты.

\section{3. Экспериментальные результаты}

Для характеризации МУНТ и Сu/МУНТ привлекались методы рентгенофазового анализа (РФА), сканирующей электронной микроскопии (СЭМ), просвечивающей электронной микроскопии высокого разрешения (ПЭМВР), а также ультрамягкой рентгеновской спектроскопии с использованием синхротронного излучения.

\section{1. Электронная микроскопия}

Для синтеза нанокомпозитов $\mathrm{Cu} / \mathrm{MУНТ} \mathrm{использовали}$ МУНТ в виде порошка (рис. 1,a), полученного при раз- 

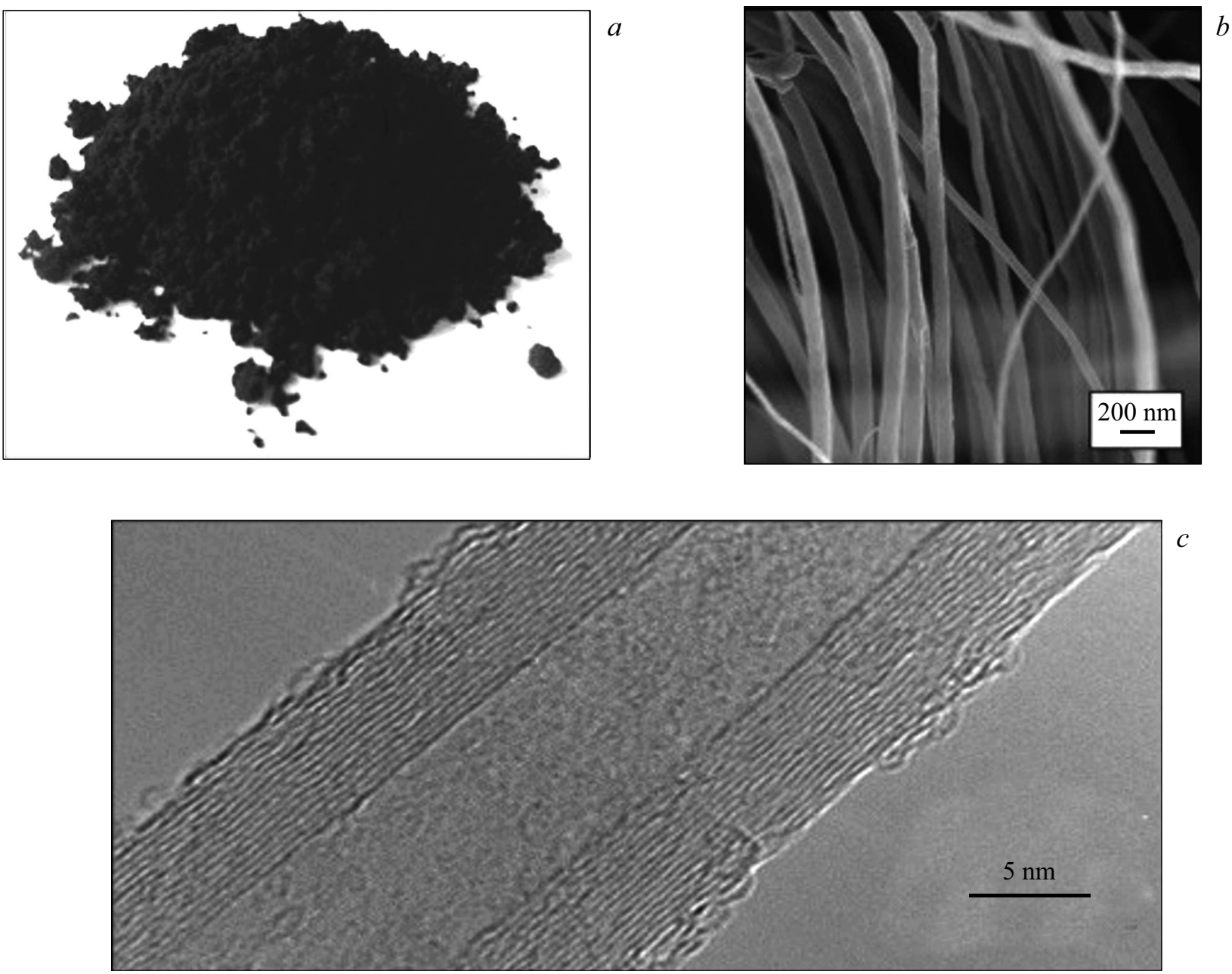

Рис. 1. Фотография порошка МУНТ, полученного при размоле массива МУНТ $(a)$, СЭМ-микрофотография пучка МУНТ (b), ПЭМВР-микрофотография МУНТ (c).



Рис. 2. СЭМ-микрофотографии образцов нанокомпозита $\mathrm{Cu} / \mathrm{MУHТ} \mathrm{с} \mathrm{низким}(a)$ и высоким $(b)$ разрешением. 




Рис. 3. ПЭМВР-микрофотография МУНТ с осажденной на ее поверхность наночастицей меди, поверхность которой окислена.

моле массива МУНТ. Синтез массива МУНТ проводили согласно методике, приведенной в работах $[14,15]$. Исследования морфологии поверхности МУНТ проведены на сканирующем электронном микроскопе Supra 50VP фирмы ZEISS (рис. 1,b).

Структура поверхности МУНТ была исследована с помощью просвечивающего электронного микроскопа высокого разрешения Carl Zeiss LIBRA 200MC (рис. 1,c). Средний внешний диаметр МУНТ составил порядка $80 \mathrm{~nm}$, длина от нескольких сотен микрон до нескольких миллиметров (рис. $1, b$ ). Боковая поверхность МУНТ сформирована графеновыми слоями, с расстояниями между ними порядка 0.34 нм и на внешней поверхности имеются дефекты в виде остаточных графеновых слоев (рис. $1, c$ ).

На рис. 2 приведены СЭМ микрофотографии нанокомпозита $\mathrm{Cu} / \mathrm{MУНТ.} \mathrm{Из} \mathrm{представленных} \mathrm{микрофотографий}$ следует, что медь равномерно осаждается на поверхности МУНТ в виде островковых покрытий (наночастиц меди). При этом наночастицы меди не имеют четкой кристаллической огранки, а имеют форму, близкую к сферической.

На ПЭМВР микрофотографии, выполненной в режиме атомного разрешения, которое достигается только для поверхностных слоев (рис. 3), видно, что поверхность таких наночастиц состоит из ядра и множества пластинчатых доменов, расположенных вокруг центрального ядра. Измеренное межплоскостное расстояние в пластинчатых доменах, равное $0.246 \mathrm{~nm}$, соответствует межплоскостному расстоянию в кристаллической закиси меди $\mathrm{Cu}_{2} \mathrm{O}$ в направлении (111).

\section{2. Рентгенофазовый анализ}

Рентгенофазовый анализ образцов проводили для исходных МУНТ и образцов композита $\mathrm{Cu} / \mathrm{MУНТ}$ при $\mathrm{Cu} K_{\alpha}$-излучении на рентгеновском дифрактометре Bruker D8 Discover в симметричной $\theta-2 \theta$ геометрии c зеркалом Гёбеля, экваториальной щелью Соллера с угловой расходимостью $2.5^{\circ}$ и щелью $1.5 \mathrm{~mm}$ на первичном пучке. Результаты исследования МУНТ с помощью РФА представлены на рис. 4, $a$. На приведенной дифрактограмме наблюдаются три пика, характерные для МУНТ $[(002),(100)$ и (004)], причем самый сильный пик в области угла $26^{\circ}$ в спектре графита соответствует дифракции на плоскостях, образуемых его $s p^{2}$-углеродными слоями (графеновыми слоями). В интервале углов $2 \Theta$ от 37 до $51^{\circ}$ градусов обнаружены небольшие пики при углах 44 и $51^{\circ}$, отнесенные к $\gamma$-Fe и к фазе карбида железа $\mathrm{Fe}_{3} \mathrm{C}$. Эти фазы локализованы во внутреннем объеме МУНТ. Для идентификации пиков использована база данных (PDF2 release 2011).

На дифрактограмме образца нанокомпозита (рис. $4, b$ ) установлено наличие фазы углеродных нанотрубок, меди $(\mathrm{Cu})$ и закиси меди $\left(\mathrm{Cu}_{2} \mathrm{O}\right)$. Межплоскостное расстояние в нанокристаллитах, окружающих основной кристалл меди, составляет $0.246 \mathrm{~nm}$, что соответствует
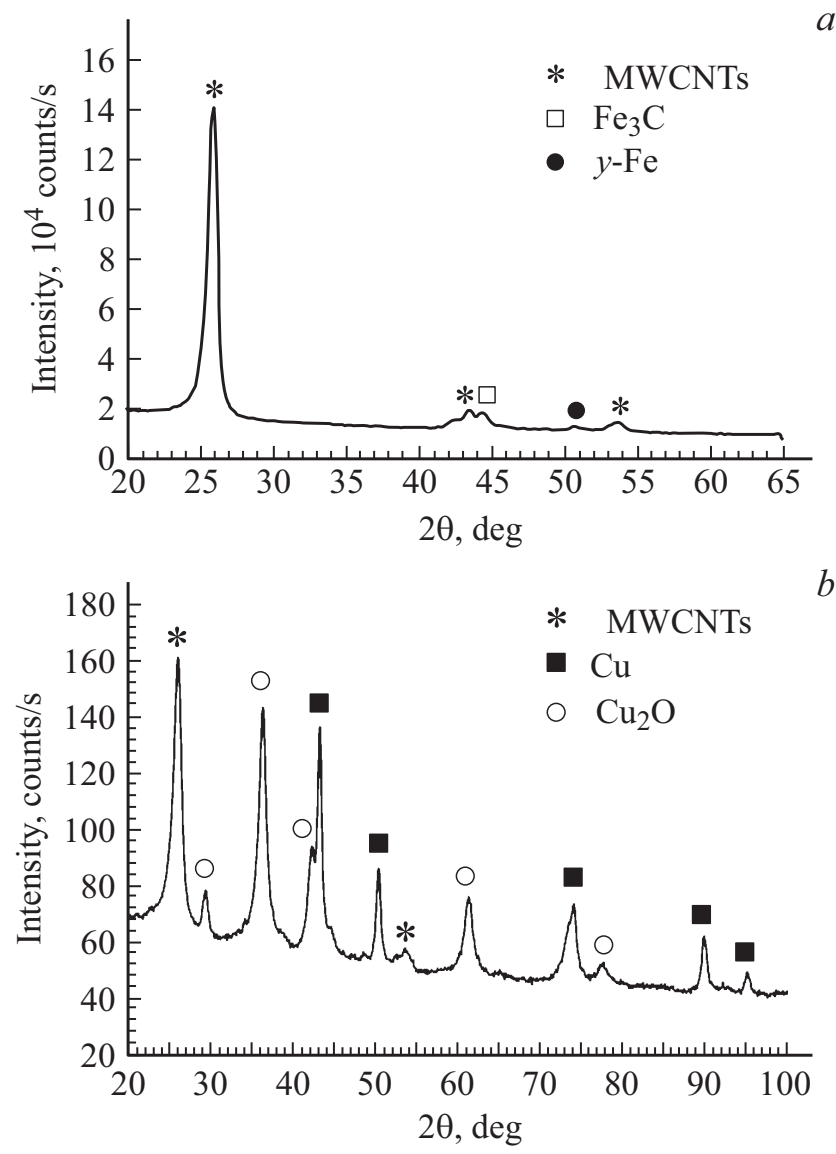

Рис. 4. Рентгеновские дифрактограммы образцов МУНТ (a) и гибридного нанокомпозита $\mathrm{Cu}_{2} \mathrm{O} / \mathrm{Cu} / \mathrm{MУHT} \mathrm{(b).}$ 
межплоскостному расстоянию в кристалле закиси меди $\left(\mathrm{Cu}_{2} \mathrm{O}\right)$ в направлении (111). Наличие в нанокомпозите фазы $\mathrm{Cu}_{2} \mathrm{O}$ может говорить о том, что данный оксид меди образовался в процессе синтеза и наиболее вероятно осажденные частицы морфологически представляют собой наночастицу меди, имеющую оболочку из закиси меди, что хорошо согласуется с результатами ПЭМВР исследований (рис. 3). Наличие в образцах этих фаз означает, что синтезированные образцы композита являются гибридным нанокомпозитом $\mathrm{Cu}_{2} \mathrm{O} / \mathrm{Cu} / \mathrm{MУHT}$.

\section{NEXAFS-спектроскопия}

NEXAFS исследования исходных МУНТ и нанокомпозита $\mathrm{Cu}_{2} \mathrm{O} / \mathrm{Cu} / \mathrm{MУHT} \mathrm{в} \mathrm{области} \mathrm{C} 1 s$ - и $\mathrm{Cu} 2 p$-краёв поглощения и обзорные измерения в широком интервале энергий квантов проводились методом полного электронного выхода (Total electron yield, TEY) с использованием синхротронного излучения Русско-Германского канала выхода и монохроматизации СИ на BESSY-II [16]. Энергетическое разрешение при изучении NEXAFS C $1 s$ и $\mathrm{Cu} 2 p$-спектров поглощения составляло 0.05 и $0.1 \mathrm{eV}$, а точность привязки элементов NEXAFS по энергии не хуже $0.1 \mathrm{eV}$. Нормировка спектров проводилась путем деления сигнала TEY образца на сигнал TEY от слоя чистого золота, деленный на сечение атома Au [17]. В обоих случаях измерения проводились с корректным учетом немонохроматического фона и коротковолнового излучения кратных порядков дифракции с использованием трансмиссионных титановых фильтров для подавления и измерения фонового излучения [18]. В качестве образцов для NEXAFS-исследований использовались мелкодисперсные порошки, которые вдавливались в металлический индий и механически фиксировались на медных держателях.

Применение метода полного электронного выхода для изучения NEXAFS позволяет эффективно проводить исследования наноразмерных слоев и интерфейса наночастица/подложка без их разрушения и модификации. Сигнал TEY в области NEXAFS формируется за счет Оже-электронов, энергия которых варьируется в пределах сотни $\mathrm{eV}$, а глубина выхода, согласно универсальной зависимости длины свободного пробега фотоэлектронов, от энергии составляет около $1 \mathrm{~nm}$ [19]. В случае таких нанокомпозитов, как $\mathrm{Cu}_{2} \mathrm{O} / \mathrm{Cu} / \mathrm{MУHT} \mathrm{метод} \mathrm{TEY} \mathrm{поз-}$ воляет одновременно исследовать с помощью NEXAFS $\mathrm{Cu} 2 p$-спектра атомно-химический состав внешних слоев наночастиц меди, а NEXAFS C1s-спектра внешнюю поверхность МУНТ, и из сравнения последнего с NEXAFS $\mathrm{C} 1 s$-спектром исходной МУНТ оценить степень модификации ее внешней поверхности.

Величина сигнала TEY прямо пропорциональна сечению поглощения (СП) рентгеновского излучения и интенсивности падающего монохроматизированного пучка СИ. При этом коэффициент пропорциональности является монотонной функцией от энергии кванта. Пола- гая этот коэффициент независимым от энергии в узкой припороговой области спектра, относительную величину сечения поглощения можно определить путем деления спектральной зависимости сигнала TEY на спектральную зависимость интенсивность падающего пучка СИ. При этом благодаря малой глубине выхода фотоэлектронов с поверхности образца искажающим влиянием „эффекта толщины“ на спектральный ход СП можно пренебречь.

Необходимым условием успешного использования метода ТЕY является измерение и подавление присутствующего в монохроматизированном излучении немонохроматического фона, состоящего из рассеянного длинноволнового ВУФ-излучения и коротковолнового излучения кратных порядков отражения от дифракционной решетки. Это особенно важно при использовании высокоинтенсивного синхротронного излучения, когда составляющая немонохроматического фона велика и приводит к появлению дополнительной структуры во втором порядке дифракции в падающем СИ. Это создает серьезные проблемы при нормировке исследуемых спектров. В настоящей работе применен оригинальный метод определения спектральной зависимости интенсивности монохроматизированного СИ в относительных единицах с корректным учетом вклада в интенсивность СИ длинноволновой рассеянной и коротковолновой кратных порядков составляющих немонохроматического фона. При этом для определения интенсивности СИ использовались фотокатод из чистого $\mathrm{Au}$, а для подавления и измерения немонохроматического фона в СИ-титановый абсорбционный фильтр в виде Ті пленки толщиной $150 \mathrm{~nm}$, закрепленной на золотой сетке. Методика получения спектральных зависимостей сечений поглощения нами ранее использовалась при изучении нанокомпозитов $\mathrm{Fe} / \mathrm{MУНТ} \mathrm{и} \mathrm{Cr} / \mathrm{MУНТ,} \mathrm{которая} \mathrm{подробно} \mathrm{описана} \mathrm{в}$ работах [4-6] и здесь не обсуждается.

На рис. 5 показаны спектральные зависимости СП в области $\mathrm{Cu} 2 p$-края поглощения композита $\mathrm{Cu} / \mathrm{MУНТ}$ после выноса на атмосферу и ряда соединений: окиси меди $\mathrm{CuO}$, закиси меди $\mathrm{Cu}_{2} \mathrm{O}$ с небольшим содержанием $\mathrm{CuO}$, металлической меди и атомарной меди [20]. Проведенные ранее исследования электронной конфигурации меди в атомном и твердотельном состояниях [20] показали, что NEXAFS в области $\mathrm{Cu} 2 p_{3 / 2}$-края поглощения очень чувствительна к степени заполнения $d$ - или $s$-подобных состояний, и позволяет легко обнаруживать изменение валентности меди. На рис. 5 показан $\mathrm{Cu} 2 p$-спектр полного фотоионного выхода (the total photoion yield, TPIY) атомов $\mathrm{Cu}$, воспроизведенный из работы [20]. Атомный спектр $\mathrm{Cu}$ отображает четкую структуру, соответствующую $2 p_{3 / 2,1 / 2} \rightarrow 4 s$ и $4 d$-переходам, со спин-орбитальным расщеплением $20 \mathrm{eV}$. При этом в спектре атома меди не обнаруживается $2 p_{3 / 2} \rightarrow 3 d$-перехода, энергетическое положение которого должно наблюдаться на $1.5 \mathrm{eV}$ выше, чем энергия $2 p_{3 / 2} \rightarrow 4 s$-перехода [22]. Следует отметить, что сечение $2 p_{3 / 2,1 / 2} \rightarrow 3 d$-возбуждения более чем в 100 раз больше 


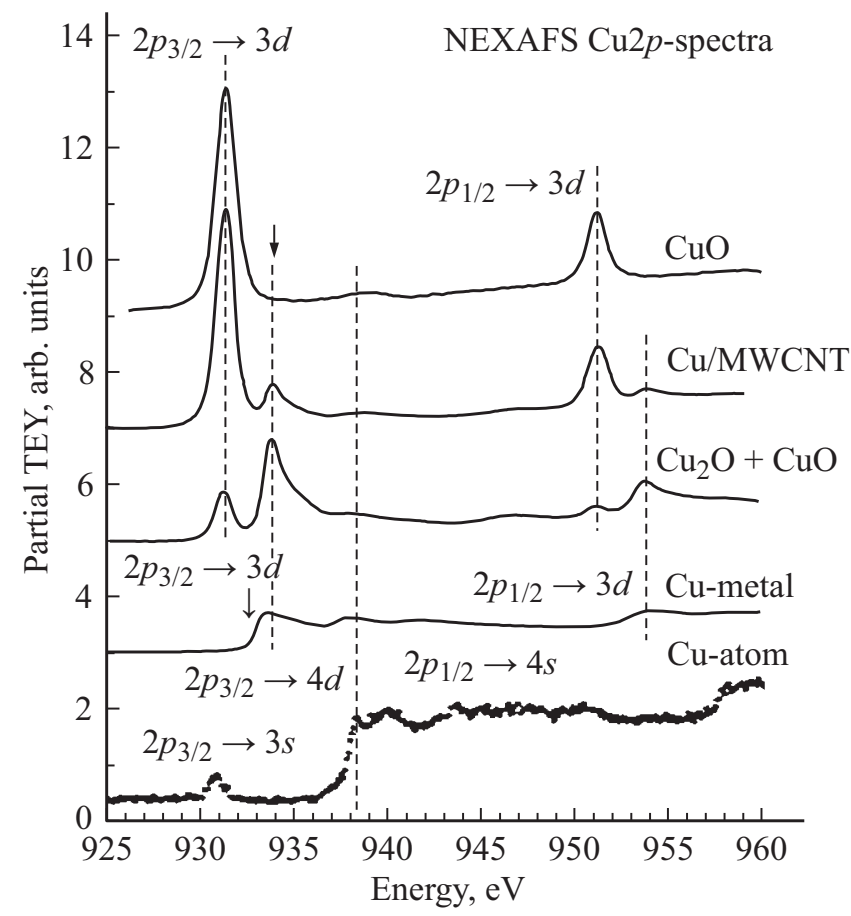

Рис. 5. NEXAFS Cu2p-спектров поглощения твердотельных соединений меди и полного фотоионного выхода ТРІY атомарной меди [20]. Стрелками указаны энергии связи $2 p_{3 / 2}$-электронов [21] в металлической меди $(932.6 \mathrm{eV})$ и оксиде $\mathrm{CuO}(933.6 \mathrm{eV})$.

сечения перехода на $4 s$-состояния [20], поэтому их появление резко изменило бы спектр. Отсутствие переходов в $3 d$-состояния ясно указывает, что в основном состоянии электронная конфигурация атомов $\mathrm{Cu}$ является $[\mathrm{Ar}] 3 d^{10} 4 s^{1}$. Тонкая структура $\mathrm{Cu} 2 p$-спектра металлической меди резко отличается от спектра атома проявлением $2 p_{3 / 2,1 / 2} \rightarrow 3 d$-переходов, что обусловлено неполным заполнением $3 d$-состояний вследствие $3 d-4 s$-гибридизации и изменением электронной конфигурации атомов меди в металле $[\operatorname{Ar}] 3 d^{10-x} 4 s^{1+x} x=0.4-4.5$ [23,24]. В приближении чисто ионной модели валентные состояния атома меди должны быть $\mathrm{Cu}^{0}$ в металле, $\mathrm{Cu}^{\mathrm{I}}$ в закиси $\mathrm{Cu}_{2} \mathrm{O}$ и $\mathrm{Cu}^{\text {II }}$ в окиси $\mathrm{CuO}$ меди, а их электронные конфигурации $[\operatorname{Ar}] 3 d^{10} 4 s^{1},[\operatorname{Ar}] 3 d^{10} 4 s^{0}$ и $[\operatorname{Ar}] 3 d^{9} 4 s^{0}$ соответственно. Однако эта модель не может быть применена к металлической меди, которая имеет не полностью заполненную $3 d$-оболочку. Влияние окисления на электронную структуру металлической меди исследовалось в работах [23-25], и было показано, что для оксидов $\mathrm{Cu}_{2} \mathrm{O}$ и $\mathrm{CuO}$ электронные конфигурации отличаются от ожидаемых в чисто ионной модели числом $3 d$-электронов порядка 9.5 и 9.35-9.4 на атом $\mathrm{Cu}$ в случае $\mathrm{Cu}_{2} \mathrm{O}$ и $\mathrm{CuO}$ соответственно. Как видно из спектров на рис. 5 основным вкладом в NEXAFS $\mathrm{Cu} 2 p$-края оксидов $\mathrm{Cu}_{2} \mathrm{O}$ и $\mathrm{CuO}$ являются $2 p \rightarrow 3 d$-переходы, как и в металле. Видно также, что край поглощения в спектре образца закиси $\mathrm{Cu}_{2} \mathrm{O}$ находится примерно в том же положении, что и металла, а край поглощения окиси $\mathrm{CuO}$ смещается в область высоких энергий примерно на $2 \mathrm{eV}$. При этом $2 p \rightarrow 3 d$-пик смещается в область перед $\mathrm{Cu} 2 p_{3 / 2}$ порогом ионизации. Резкое увеличение интенсивности первой полосы в NEXAFS $2 p$-спектре $\mathrm{CuO}$ происходит в результате кулоновского взаимодействия между сильно локализованными рентгеновской $2 p$-вакансией и возбужденного $3 d$-электрона. Конечным состоянием является так называемый „остовный экситон“ (core exciton), что подтверждается данными XPS [23]: наблюдаемый пик в $\mathrm{Cu} 2 p$-спектре поглощения $\mathrm{CuO}$ ниже энергии связи $\mathrm{Cu} 2 p_{3 / 2}$-электрона (отмечено стрелкой на рис. 5). Приведенные на рисунке $\mathrm{Cu} 2 p$-спектры атома, металла и оксидов меди наглядно показывают, что NEXAFS $\mathrm{Cu} 2 p$-спектров поглощения дают информацию о степени окисления и заполнения $3 d$-состояний в соединениях меди. Анализ формы спектров и энергетических положений элементов тонкой структуры Cu2p-спектра композита определенно демонстрируют, что на поверхности нанотрубок присутствуют оксиды $\mathrm{CuO}$ и $\mathrm{Cu}_{2} \mathrm{O}$. Это хорошо видно из сравнения NEXAFS $\mathrm{Cu} 2 p$ спектров поглощения металлической меди, оксида $\mathrm{CuO}$ и образца закиси меди $\mathrm{Cu}_{2} \mathrm{O}$ с небольшой примесью $\mathrm{CuO}$.

Рентгенофазовый анализ образцов композита, не имевших контакта с атмосферным кислородом, показал наличие на поверхности МУНТ медных металлических частиц в окружении наночастиц закиси меди. Вероятно, $\mathrm{CuO}$ формируется на поверхности наночастиц меди под действием атмосферного кислорода. Как отмечалось ранее при анализе данных СЭМ (см. рис. 2) покрытие из меди оказывается не сплошным, а в виде наночастиц разного размера, которые обладают хорошей адгезией к внешней поверхности МУНТ. Это указывает на наличие химического взаимодействия между частицами и внешними графеновыми слоями МУНТ. В связи с этим представляется интересным сопоставление NEXAFS C1s-спектров поглощения исходной МУНТ и композита после выноса на атмосферу.

На рис. 6 приведены спектральные зависимости парциальных $\mathrm{C} 1 s$ сечений поглощения МУНТ и нанокомпозита $\mathrm{Cu} / \mathrm{MУHT,} \mathrm{а} \mathrm{также} \mathrm{исследованных} \mathrm{ранее}$ композитов $\mathrm{Cr} / \mathrm{MУHT} \mathrm{и} \mathrm{Fe} / \mathrm{MУHT} \mathrm{[4-6].} \mathrm{На} \mathrm{рис.} 6$ хорошо видно, что в спектре композита сохраняются элементы структуры ( $\pi$ и $\sigma$ резонансы), характерные для спектра исходной МУНТ, что указывает на отсутствие существенной деструкции внешних слоев МУНТ. Однако в промежуточной между $\pi$ и $\sigma$ резонансами энергетической области $285.4-291.8 \mathrm{eV}$ обнаруживается дополнительная структура в виде широкой полосы, малоинтенсивного пика и наплыва с энергиями 277.5, 288.4 и $290.4 \mathrm{eV}$ соответственно. Положения этих пиков хорошо согласуется с энергетическими положениями элементов NEXAFS C1s-спектра поглощения оксида графита $[26,27]$ соответствующих эпоксидным $(\mathrm{C}-\mathrm{O}-\mathrm{C})$ и двойным $(\mathrm{C}=\mathrm{O}, \mathrm{O}-\mathrm{C}-\mathrm{O})$ связям и карбонатной группы $\left[\mathrm{CO}_{3}\right]^{2-}[28]$. 


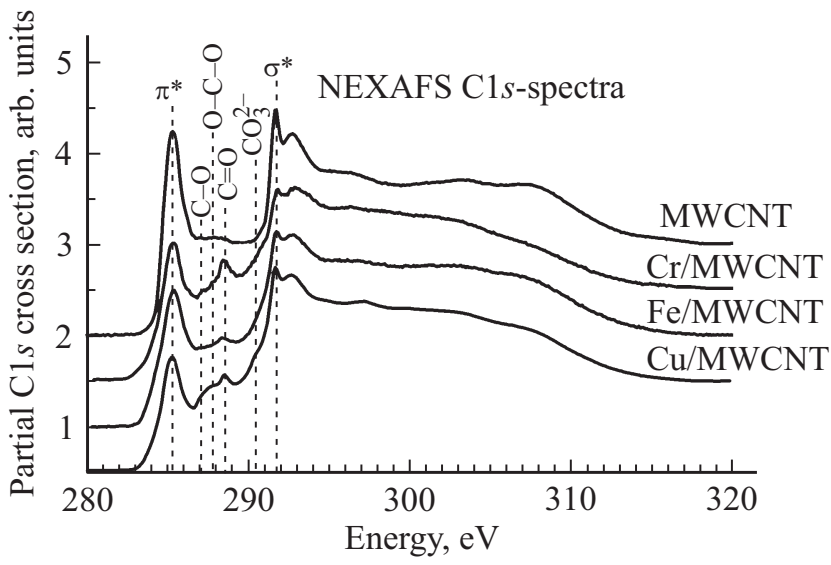

Рис. 6. NEXAFS C1s-спектров поглощения композитов Cr/МУНТ [6], Fe/МУНТ [4] и Сu/МУНТ.

Принимая это во внимание, хорошую адгезию частиц меди к МУНТ можно объяснить образованием химической связи через атомы кислорода между оксидом и внешней поверхностью МУНТ. Явное сходство тонкой структуры $\mathrm{C} 1 s$-спектров композитов позволяет интерпретировать изменения в спектре композита по сравнению со спектром исходной нанотрубки, как результат образования химической связи между атомами углерода из внешнего слоя МУНТ и атомами кислорода осажденных медьсодержащих наночастиц. В отличие от композитов $\mathrm{Cr} / \mathrm{MУHT} \mathrm{и} \mathrm{Fe} / \mathrm{MУHT,} \mathrm{где} \mathrm{покрывающие} \mathrm{на-}$ норазмерные слои оксидов $\mathrm{Cr}_{2} \mathrm{O}_{3}$ и $\mathrm{Fe}_{3} \mathrm{O}_{4}$ оказываются сплошными, поверхность композита $\mathrm{Cu} / \mathrm{MУНТ} \mathrm{только}$ частично покрыта частицами меди (см. рис. 2). Поэтому $\mathrm{C} 1 s$-спектр $\mathrm{Cu} / \mathrm{MУНТ} \mathrm{представляет} \mathrm{собой} \mathrm{суммарный}$ спектр открытой поверхности многостенной нанотрубки, спектра интерфейса между наночастицей меди и внешней поверхностью нанотрубки и спектра поверхности крупных частиц, размеры которых больше глубины выхода рентгеновских фотоэлектронов и вторичных электронов, то есть порядка $100 \mathrm{~nm}$ и более. Не смотря на большое сходство тонкой структуры $\mathrm{C} 1 s$-спектров композитов хрома, железа и меди, имеются некоторые различия, в частности, в спектрах композитов хрома и меди наблюдается заметная ступенька на подъеме сечения поглощения перед $\sigma$-резонансом, энергетическое положение которого $(290.4 \mathrm{eV})$ хорошо согласуется с энергией $\pi$-резонанса в плоском анионе $\left[\mathrm{CO}_{3}\right]^{2-}[28,29]$. Об участии функциональных групп кислорода, которые формируются в процессе термического разложения металлорганических соединений на графеновых поверхностях, в образованиях химических связей между графеном и частицами металлов и их оксидами отмечается и в других работах [30,31], в которых проводились исследования взаимодействия наночастиц меди приготовленных методом MOCVD на поверхности оксида графена и MУНТ методами XPS- и NEXAFS-спектроскопии. В работе [30] на основании появления полосы с энергией
$531.7 \mathrm{eV}$ в фотоэлектронном O1s-спектре сделан вывод, что ступенька с энергетическим положением $290.4 \mathrm{eV}$ в NEXAFS C $1 s$-спектра композита $\mathrm{CuO} /($ оксид графенового слоя) обусловлена формированием связи $\mathrm{Cu}-\mathrm{O}-\mathrm{C}$. Однако не очевидно, что присоединение атома меди к группе $\mathrm{C}-\mathrm{O}$ будет приводить к сдвигу соответствующей полосы поглощения в область больших энергий на $3 \mathrm{eV}$, наоборот должно наблюдаться „красное“ смещение [32]. Существенно отметить, что положение полосы в XPS $\mathrm{O} 1 s$-спектре этой работы близко к величине характерной для карбонатной группы $531.5 \mathrm{eV}$ в карбонате меди $\mathrm{CuCO}_{3}$ [21]. В работе [31] проводились исследования нанокомпозита $\mathrm{SnO} / \mathrm{MУНT}$ до и после облучения ионами аргона и было показано, что в результате облучения в NEXAFS C1s-спектра композита формируется спектральная особенность с энергией $290.4 \mathrm{eV}$, которую авторы ссылаясь на данные работы [30] связывают с образованием связи $\mathrm{Sn}-\mathrm{O}-\mathrm{C}$. При этом авторы указывают на появление в XPS O1s-спектре облученного композита полосу с энергией $530.7 \mathrm{eV}$, которая входит в область энергий связи $531.5-532.5 \mathrm{eV}$, характерную для карбонатной группы в различных соединениях [21]. Принимая во внимание вышесказанное, появление элемента тонкой структуры с энергией $290.4 \mathrm{eV}$ в NEXAFS $\mathrm{C} 1 s$-спектра поглощения композита $\mathrm{Cu} / \mathrm{MУНT} \mathrm{сдеду-}$ ет связать с образованием аниона $\left[\mathrm{CO}_{3}\right]^{2-}$. Возможность образования таких анионов на поверхности оксида графита подтверждена экспериментально методами NEXAFS-спектроскопии [33]. Следует также отметить, что первоначально при осаждении в инертной атмосфере аргона на внешней поверхности MWCNT осаждается металлическая медь. Это дает основания полагать возможность образования карбидов меди и тем самым частично объяснить хорошую адгезию наночастиц меди к поверхности МУНТ формированием связи $\mathrm{Cu}-\mathrm{C}$. Однако тонкая структура карбидов $3 d$-переходных металлов накладывается на NEXAFS C1s-спектров поглощения их оксидов [34], потому необходимо в будущем провести исследования композитов металл/МУНТ методами фотоэлектронной спектроскопии.

\section{5. Заключение}

Исследования нанокомпозитов $\mathrm{Cu} / \mathrm{MУНТ,} \mathrm{проведен-}$ ные методами рентгеновской дифрактометрии и ультрамягкой рентгеновской спектроскопии, продемонстрировали взаимодополняемость этих методов при изучении наноструктурированных материалов. Показано, что разработанная технология нанесения на поверхность МУНТ наночастиц меди является эффективной для приготовления композитных материалов. Установлено, что в инертной атмосфере аргона наночастицы меди осаждаются на поверхности МУНТ в виде частиц разного размера, состоящих из ядра металлической меди и оболочки из закиси меди. Однако после выноса на атмосферу на поверхности наночастиц частиц меди 
наблюдается образование оксида меди $\mathrm{CuO}$. Показано, что хорошая адгезия наночастиц меди на поверхности МУНТ обеспечивается образованием химической связи между атомами углерода внешнего графенового слоя нанотрубки и атомами кислорода оксида меди $\left(\mathrm{Cu}_{2} \mathrm{O}\right)$, покрывающего ядро наночастицы.

\section{Финансирование работы}

Работа выполнена при финансовой поддержке двухсторонней программы RGBL на BESSY II, грантов РФФИ № 19-32-5062/19 мол_нр и № 18-33-00776, поддержанного РФФИ, программы фундаментальных исследований УрО РАН, проект № 18-10-2-23, в рамках выполнения Госзадания ИМХ РАН тема 45.8 и при использовании оборудования ЦКП „Физика и технология микро- и наноструктур“.

\section{Конфликт интересов}

Авторы заявляют, что у них нет конфликта интересов.

\section{Список литературы}

[1] C.N.R. Rao, A.K. Cheetham. J. Mater. Chem. 11, 2887 (2001).

[2] D. Eder. Chem. Rev. 110, 1348 (2010).

[3] А.В. Кадомцева, А.В. Воротынцев, В.М. Воротынцев, А.Н. Петухов, А.М. Объедков, К.В. Кремлев, Б.С. Каверин. ЖПХ 88, 563 (2015).

[4] V.N. Sivkov, S.V. Nekipelov, O.V. Petrova, A.M. Obiedkov, B.S. Kaverin, A.I. Kirillov, G.A. Domrachev, V.A. Egorov, S.A. usev, D.V. Vyalikh, S.L. Molodtsov. Fuller., Nanotub., Carbon Nanostructures 23, 17, (2015).

[5] В.Н. Сивков, А.М. Объедков, О.В. Петрова, С.В. Некипелов, К.В. Кремлев, Б.С. Каверин, Н.М. Семенов, С.А. Гусев. ФТТ 57, 185(2015).

[6] O.V. Petrova, S.V. Nekipelov, A.E. Mingaleva, V.N. Sivkov, A.M. Obiedkov, B.S. Kaverin, K.V. Kremlev, S.Yu. Ketkov, S.A. Gusev, D.V. Vyalikh, S.L. Molodtsov. J. Phys.: Conf. Ser. 741, 012038 (2016).

[7] К.В. Кремлев, А.М. Объедков, С.Ю. Кетков, Б.С. Каверин, Н.М. Семенов, С.А. Гусев, Д.А. Татарский, П.А. Юнин. Письма в ЖТФ 42, 10, 40 (2016).

[8] К.В. Кремлев, А.М. Объедков, С.Ю. Кетков, Б.С. Каверин, Н.М. Семенов, Г.А. Домрачев, С.А. Гусев, Д.А. Татарский, П.А. Юнин. Поверхность. Рентгеновские, синхротронные и нейтронные исследования, 7, 45 (2015).

[9] К.В. Кремлев, А.М. Объедков, Н.М. Семенов, Б.С. Каверин, С.Ю. Кетков, С.А. Гусев, П.А. Юнин, А.И. Елкин, А.В. Аборкин. Письма в ЖТФ 44, 19, 24 (2018).

[10] Б.С. Каверин, А.М. Объедков, С.Ю. Кетков, К.В. Кремлев, Н.М. Семенов, С.А. Гусев, Д.А. Татарский, П.А. Юнин, И.В. Вилков, М.А. Фаддеев. Поверхность. Рентгеновские, синхротронные и нейтронные исследования 7, 54 (2018).

[11] Химия и технология редких и рассеянных элементов. / Под ред. К.А. Большакова. Высш. шк., М. (1976). Ч. 1. $360 \mathrm{c}$.

[12] В.М. Воротынцев, А.В. Гусев, Г.Г. Девятых. Высокочистые вещества 1,5 (1988).
[13] В.Н. Сивков, А.А. Ломов, А.Л. Васильев, С.В. Некипелов, О.В. Петрова. ФТП 47, 8, 1048 (2013).

[14] А.И. Кириллов, А.М. Объедков, В.А. Егоров, Г.А. Домрачев, Б.С. Каверин, Н.М. Семенов, Т.И. Лопатина, С.А. Гусев, А.Д. Мансфельд. Нанотехника 1 (25), 72 (2011).

[15] А.М. Объедков, Б.С. Каверин, В.А. Егоров, Н.М. Семенов, С.Ю. Кетков, Г.А. Домрачев, К.В. Кремлев, С.А. Гусев, В.Н. Перевезенцев, А.Н. Москвичев, А.А. Москвичев, А.С. Родионов. Письма о материалах 2, 152 (2012).

[16] S.A. Gorovikov, S.L. Molodtsov, R. Follath. Nucl. Instrum. Methods Phys. Res. A 441, 506 (1998).

[17] B.L. Henke, E.M. Gullikson, J.L. Devis. At. Data. Nucl. Data.Tables 54, 181 (1993).

[18] K. Kummer, V.N. Sivkov, D.V. Vyalikh, V.V. Maslyuk, A. Bluher, S.V. Nekipelov, T. Bredow, I. Mertig, M. Mertig, S.L. Molodtsov. Phys. Rev. B 80, 155433-11 (2009).

[19] J. Stohr. NEXAFS spectroscopy. Springer, Berlin (1992). $403 \mathrm{p}$.

[20] U. Arp, K. Iemura, G. Kutluk, M. Meyer, T. Nagata, M. Sacchi, B. Sonntag, S. Yagi, A. Yagishita. J. Phys. B 27, 3389, (1994).

[21] Handbook of X-ray Photoelectron Spectroscopy. Ed. Jill Chastain Roger C. King. Physical Electronics, Inc. 6509 Plying Cloud Drive Eden Prairie, Minnesota, 55344 United State of America (1995). $261 \mathrm{p}$.

[22] O. Cheshnovsky, K.J. Taylor, J. Conceicao, R.E. Smalley. Phys. Rev. Lett. 64, 1785 (1990)

[23] M. Grioni, J.B. Goedkoop, R. Schoorl, F.M.F. de Groot, J.C. Fuggle, F. Schäfers, E.E. Koch, G. Rossi, J.-M. Esteva, R.C. Karnatak. Phys. Rev. B 39, 1541, (1989).

[24] H. Ebert, J. Stöhr, S.S.P. Parkin, M. Samant, A. Nilsson. Phys. Rev. B 53, 16067, (1996).

[25] M. Grioni, M.T. Czyžyk, F.M.F. de Groot, J.C. Fuggle, B.E. Watts. Phys. Rev. B 39, 4886 (1989).

[26] M. Grioni, J.F. van Acker, M.T. Czyžyk, J.C. Fuggle. Phys. Rev. B 45, 3309 (1992).

[27] H.-K. Jeong, H.-J. Noh, J.-Y. Kim, M.H. Jin, C.Y. Park, Y.H. Lee. Europhys. Lett. 82, 67004 (2008).

[28] R.J. Madix, J.L. Solomon, J. Stöhr, Surf. Sci. 197, L253 (1988).

[29] K. Benzerara, N. Menguy, P. López-García, T.-H. Yoon, J. Kazmierczak, T. Tyliszczak, F. Guyot, G.E. Brown. Proc. Natura Acad. Sci. USA 103, 9440 (2006).

[30] X. Zhang, J. Zhou, H. Song, X. Chen, Yu.V. Fedoseeva, A.V. Okotrub, L.G. Bulusheva. ACS Appl. Mater. Interfaces 6, 19, 17236 (2014).

[31] S.N. Nesov, P.M. Korusenko, S.N. Povoroznyuk, V.V. Bolotov, E.V. Knyazev, D.A. Smirnov. Nucl. Instrum. Meth. Phys. Res. B 410, 222 (2017).

[32] А.В. Генералов, М.М. Бржезинская, А.С. Виноградов, R.P Puttner, M.B. Чернышева, А.В. Лукашин, А.А. Елисеев. ФTT 53, 598 (2011).

[33] J. Diaz, S. Anders, A. Cossy-Favre, M. Samant, J. Stohr. J. Appl. Phys. 9, 8265 (2001).

[34] J.G. Chen. Surf. Sci. Rep. 30, 1-152 (1997).

Редактор Ю.Э. Китаев 